\title{
Mantle Cell Lymphoma associated with Membranoproliferative and Membranous Glomerulonephritis: Report of Two Cases
}

\author{
Elena Zakharova ${ }^{1 *}$, Ekaterina Stolyarevich ${ }^{2}$, Eugeny Nikitin ${ }^{3}$ \\ ${ }^{1}$ Nephrology Department, Head, Moscow City Botkin Memorial Hospital \\ ${ }^{2}$ Nephropathology Department, Head, Moscow City Nephrology Centre \\ ${ }^{3}$ Hematology Day Patient Department, Head, Moscow City Botkin Memorial Hospital
}

Received: 08 November, 2016; Accepted: 16 November, 2016; Published: 26 November, 2016

*Corresponding author: Elena Zakharova, Department of Nephrology, Head; City Botkin Memorial Hospital; Moscow, Russian Federation,

\begin{abstract}
Mantle Cell Lymphoma (MCL) is an aggressive lymphoid neoplasm, representing 5-10\% of all B-cell Non-Hodgkin lymphomas and characterized by the proliferation of mature B-lymphocytes, that infiltrate lymphoid tissues, bone marrow, peripheral blood, and extranodal sites. Kidney involvement in MCL, reported rarely in living patients, is caused either by direct lymphoid infiltration or by multiple mechanisms (cytokines, immune complexes etc.) triggering paraneoplastic Glomerulonephritis (GN). 13 biopsy-proven cases described so far represent various patterns of GN, including 4 cases of Membranoproliferative Glomerulonephritis (MPGN). We didn't find any data, reporting membranous nephropathy (MN) in MCL.

We present two cases of MCL with GN, diagnosed on the basis of renal biopsy findings, one case of MPGN and another with MN. In both cases renal disease manifestations dominated in the clinical presentation, which demanded kidney biopsy. Pathology patterns of immune-complex MPGN and MN defined high index of suspicion for malignant disease and guided targeted search, resulted in MCL diagnosis. Patient with MCL-associated MPGN, treated with rituximab and bendamustine, reached complete MCL remission and partial remission of GN. Patient with MCL-associated MN, treated with ribomustine and rituximab reached partial remission of nephrotic syndrome with complete restoration of kidney function. To our knowledge this is the first description of MN in patients with MCL.
\end{abstract}

Keywords: Lymphoma; Glomerulonephritis; Renal biopsy; Chronic kidney disease

\section{Introduction}

Renal involvement in patients with Non-Hodgkin Lymphomas (NHL) with a broad spectrum of clinical and pathology variants has been widely described in the literature. Clinical presentations include Acute Kidney Injury (AKI), Nephrotic Syndrome (NS), proteinuria and/or hematuria, arterial hypertension or Chronic Kidney Disease (CKD). Renal manifestations may precede, coexist, or follow the diagnosis of NHL by several years; therefore kidney biopsy is crucial for the diagnosis. However, the number of pathology-proven cases is limited; most common pathology patterns, reported in the literature, are represented by interstitial or glomerular specific infiltration and paraneoplastic glomerulonephritis (GN) - mainly Membranous Nephropathy (MN) and Membranoproliferative Glomerulonephritis (MPGN), and rarely Minimal Change Disease (MCD), Focal Segmental Glomerulosclerosis (FSGS) and Crescentic Glomerulonephritis (CGN) [1-10].

Mantle Cell Lymphoma (MCL) is an aggressive lymphoid neoplasm, representing 5-10\% of all B-cell NHL and characterized by the proliferation of mature B-lymphocytes, that infiltrate lymphoid tissues, bone marrow, peripheral blood, and extranodal sites. The hallmark of this lymphoma is translocation $t(11 ; 14)$ (q13; q32), which results in overexpression of Cyclin D1 [11]. Kidney involvement in MCL, reported rarely in living patients, is caused either by direct lymphoid infiltration or by multiple mechanisms (cytokines, immune complexes etc.) triggering paraneoplastic GN. Data retrieval allowed us to find 17 biopsyproven cases, have been described in the literature so far: 3 cases of renal MCL infiltration, 1 case of interstitial nephritis without lymphoid infiltration, 5 cases of proliferative GN, 1 case of MCD, 1 case of FSGS, 1 case of MPGN, 1 case of CGN, and 4 cases with the combination of MCL infiltration and GN ( 3 with MPGN and 1 with CGN) [12-26]. We didn't find any data, reporting membranous nephropathy in MCL.

Here we present two cases of MCL with GN, diagnosed on the basis of renal biopsy findings, one case of MPGN and another with $\mathrm{MN}$, and discuss the diagnostics difficulties and treatment results.

\section{Case Presentation}

\section{Case 1}

Caucasian female, year of birth 1948, first admitted to our nephrology unit April 62011.

Main complains: weakness, pedal edema, weight loss.

Previous medical history: urinary tract infection, two 
normal pregnancies, uterine adenomyosis, total hysterectomy in 1997, cholecystectomy in 1999, mild arterial hypertension

History of present illness: March 2010 after respiratory illness she developed mild pedal edema, outpatient evaluation and work-up found enlarged inguinal lymph nodes, proteinuria $0.3 \mathrm{~g} / \mathrm{L}$ and microhematuria with normal kidney function tests, mild anemia and LDH elevation. She received diuretics and iron supplements, her edema persisted and she noted significant weight loss - 16 kilograms during 11 months.

February 2011 after respiratory illness with high-grade fever her proteinuria increased to $6.0 \mathrm{~g} / \mathrm{L}$, she was admitted to the local hospital. Work-up found Hb $9.9 \mathrm{~g} / \mathrm{dL}$, ESR $120 \mathrm{~mm} /$ hour, serum creatinine $179 \mu \mathrm{mol} / \mathrm{L}$, urea $8.8 \mathrm{mmol} / \mathrm{L}$, total protein 5.6 $\mathrm{g} / \mathrm{dL}$, LDH $551 \mathrm{U} / \mathrm{L}$, other total blood count and blood chemistry tests, as well as coagulation tests were within normal range. Proteinuria spontaneously decreased to $2.0 \mathrm{~g} / \mathrm{L}$, urine sediment contained RBC 90-100 hpf. Electrocardiogram was normal, echocardiography showed mild left ventricular hypertrophy. Kidney, abdomen and pelvis ultrasound were unremarkable but solitary liver cyst. Thyroid gland ultrasound revealed nodular goiter with slightly enlarged regional lymph nodes (thyroid hormones within normal range). Plain chest and skeletal X-ray didn't find anything significant; however total body CT revealed mediastinal and abdominal lymph nodes enlargement. Serum and urine immunochemistry detected high $\beta 2$-microglobuline level, increase of circulating immune complexes, containing IgG, IgA, IgM and C3, and traces of Bence-Jones kappa light chains in the urine. She was referred to our clinic for kidney biopsy.

At admission: conscious, alert, slightly depressed. Body temperature $36.9^{\circ} \mathrm{C}$, RR 18 per minute, pulse regular 80 per minute, BP 150/80 mm Hg. Pale, slightly undernourished, with moderate pedal edema. HEENT otherwise normal. Single small, soft, painless right anterior cervical lymph node, other peripheral lymph nodes not felt. Lungs: clear. Heart: regular rhythm, no murmur. Abdomen soft, non-tender, bowel sounds normal. Liver, spleen and kidneys not felt. Urine normally coloured, urine output $800 \mathrm{ml} / 24$ hours. Routine work-up data were consistent with the previous evaluation.

\section{Kidney Biopsy}

Light microscopy: sections of formalin fixed paraffinembedded tissue were stained with H\&E, Masson's trichrome, periodic acid-Shiff and Congo red. 11 glomeruli were found, all of them enlarged, with lobular appearance due to the mesangial and endocapillary proliferation. Capillary walls thickened, some of them double-contoured [Figure 1]. Interstitial edema, diffusefocal intensive interstitial infiltration with lymphocytes and neutrophils [Figure 2]. Arteries and arterioles otherwise normal. Congo red staining was negative.

Immunofluorescence: on unfixed cryo-sections with fluorescein conjugated anti IgA, IgG, IgM, C1q, C3, fibrinogen, lambda and kappa light chains antibodies demonstrated positive $(+++)$ staining for IgG, C1q, C3, lambda and kappa light chains on

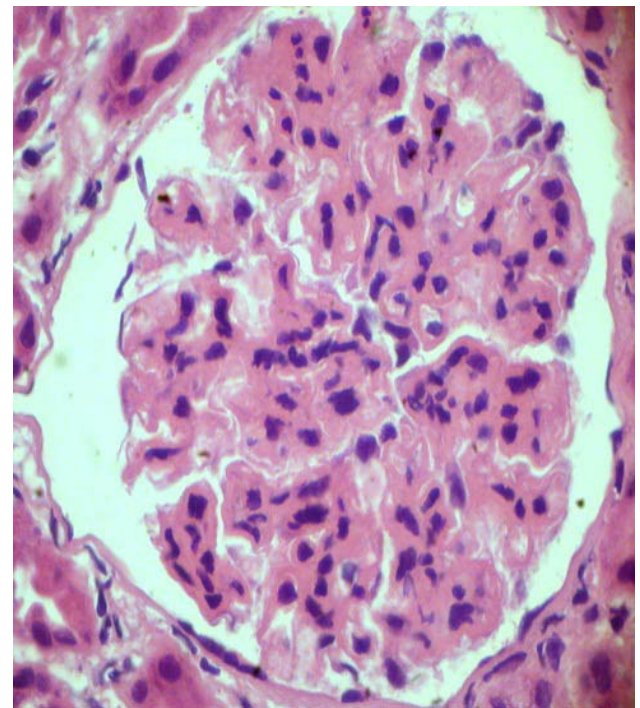

Figure 1: Light microscopy. Glomerulus lobular appearance, mesangial and endocapillary proliferation, capillary walls thick, some of them double-contoured. H\&E x200.

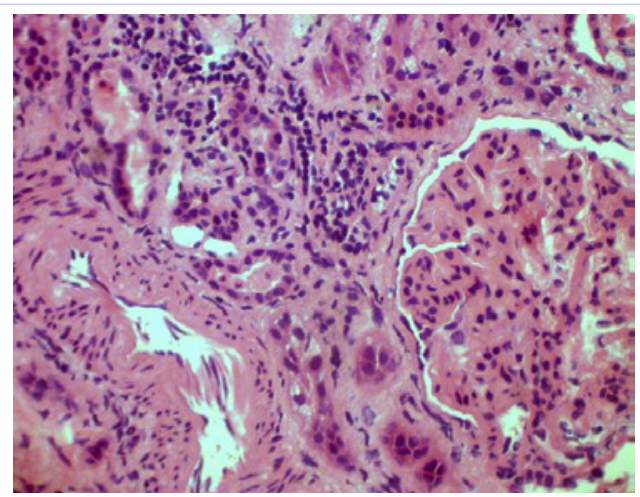

Figure 2: Case 1: light microscopy. Diffuse-focal intensive interstitial infiltration with lymphocytes and neutrophils, glomerulus lobular appearance. H\&E x200.

the periphery of capillary loops, and negative staining for $\operatorname{IgA}$, IgM and fibrinogen.

Pathologists Conclusion: Membranoproliferative glomerulonephritis.

\section{Additional Work-Up}

Autoimmune screening: anti-DNA, antinuclear antibodies, rheumatoid factor, C3 and C4 within normal range, cryoglobulines not detected.

Infections screening: RPR-test for Treponema Pallidum, HBsAg, anti-HCV and anti-HIV-antibodies and tuberculin skin test - all negative, CRP within normal range.

Repeated Serum and Urine Immunochemistry: Immunoglobulines within normal range, non-selective glomerular proteinuria $3.0 \mathrm{~g} / 24$ hours, monoclonal secretion not detected. 
Peripheral Lymph Nodes Ultrasound: multiple hypoechoic cervical, submandibular and axillary lymph nodes 6-17 $\mathrm{mm}$ in diameter.

Gastroduodenoscopy with Duodenal Biopsy: gastroduodenitis, duodenal nodular lymphoid hyperplasia. Pathology didn't find any specific lymphoid infiltration or other malignancy.

Colonoscopy: colon diffuse follicular hyperplasia.

Bone Marrow Biopsy (light microscopy): Medullary spaces are wide, adipose tissue prevail on the hematopoietic, sometimes to the extent of total filling of medullary space with adipocytes. The number of all three normal hematopoetic lineage cells is decreased, granulocytic lineage prevailing with normal maturation. Megakaryocytes are few in number. Lymphoid hyperplasia is not seen.

Thyroidectomy: with pathology evaluation of thyroid tissue and lymph nodes: adenomatous macro- normofollicular goiter, reactive lymphoid hyperplasia.

ClinicalDiagnosis: Immune-complex membranoproliferative glomerulonephritis, nephritic syndrome with impaired renal function. Lymphadenopathy of undefined origin.

Follow-up: during the next 4 years the patient was regularly evaluated in the outpatient setting. She was receiving L-thyroxin ARB's and diuretics, and doing well. Her edema resolved; blood pressure was well controlled; she gained 4 kilograms of weight. Repeated serum and urine immunochemistry, kidney and abdomen ultrasound, chest CT and gastroscopy did not show any significant changes. At the follow-up visit in April 2015 her proteinuria decreased to $1.3 \mathrm{~g} / 24$ hours, her total protein became normal and creatinine decreased to $106 \mu \mathrm{mol} / \mathrm{L}$.

July 2015 she developed high-grade fever, face puffiness and neck lymph nodes enlargement, which resolved spontaneously. August 2015 she again developed fever with her legs flush skin, resolved spontaneously. September 2015 she developed chill, nausea, skin rush, loin erythema, and was re-admitted to our nephrology unit October 12016.

At second admission: Conscious, alert. Body temperature $37.1^{\circ} \mathrm{C}$, RR 19 per minute, pulse regular 64 per minute, BP 150/90 $\mathrm{mm} \mathrm{Hg}$. Pale, normally nourished, mild pedal edema. Prominent loin erythema [Figure 3], skin hyperpigmentation of both legs. HEENT otherwise normal. Multiple small, soft and painless peripheral lymph nodes and single large right supraclavicular

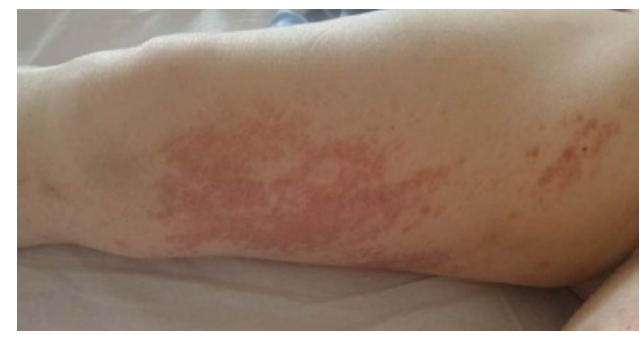

Figure 3: Case 1: Skin rush. lymph node $>20 \mathrm{~mm}$. Lungs: clear. Heart: regular rhythm, no murmur. Abdomen soft, non-tender, bowel sounds normal. Liver, spleen and kidneys not felt. Urine normally coloured, urine output $1400 \mathrm{ml} / 24$ hours.

\section{Further Work-Up}

Routine Tests: Hb $9.3 \mathrm{~g} / \mathrm{dL}$, ESR $63 \mathrm{~mm} /$ hour, serum creatinine $109 \mu \mathrm{mol} / \mathrm{L}$, LDH $549 \mathrm{U} / \mathrm{L}$, other total blood count and blood chemistry parameters within normal range; proteinuria $2.08 \mathrm{~g} / \mathrm{L}-2.65 \mathrm{~g} / 24$ hours, RBC 8-10 hpf.

Repeated serum and urine immunochemistry: polyclonal hypergammaglobulinemia (IgA $5.28 \mathrm{~g} / \mathrm{L}, \operatorname{IgG} 32.5 \mathrm{~g} / \mathrm{L}$ ) with the increase of circulating immune complexes. Rheumatoid factor $128 \mathrm{IU} / \mathrm{mL}$. Glomerular proteinuria $2.86 \mathrm{~g} / 24$ hours. Cryoglobulines and monoclonal secretion not detected.

Repeated Peripheral Lymph Nodes Ultrasound: multiple cervical, submandibular, sub- and supraclavicular, axillary and inguinal lymph nodes, single and within conglomerates (diameter 8-32 $\mathrm{mm}$ ), with thickened cortex.

Repeated Abdomen CT: multiple upper-diaphragmal, paracaval, paragastral, paraaortal, mesenterial, paracolon and Iliac Lymph Nodes (diameter 8-17 mm), mild splenomegaly (maximal oblique slice square $31.5 \mathrm{~cm} 2$ ). Other findings unremarkable but solitary liver cyst 22x19 mm.

\section{Cervical lymph node biopsy}

Light Microscopy: subtotal effacement of the lymph node architecture with follicle-like structures with rather narrow germinal centers and distinctly expanded mantle zone, presented with small lymphoid cells with the uniform disperse chromatin pattern and angular nuclei; with confluence areas in the interfollicular zone. Some follicles demonstrate germinal centers colonization by small lymphoid cells with irregular nuclei form. Throughout some spread intermediate sinuses are contoured and filled with hystocytes with admixture of small lymphoid cells.

Immunohistochemistry: using anti CD5, CD10, CD20, CD23, BCL-2, BCL-6, Ki-67 and CyclinD1 antibodies: folliclelike structures cells express CD20, cells of distinctly expanded mantle zone with confluent areas and proliferates formation in the cortical zone express CD\%, CyclinD1, BCL-2. Reaction with anti CD10 and BCL- 6 antibodies in malignant cells are negative (positive are only cells of colonized preexisting follicles light germinal centers). Proliferative activity index Ki-67 is average $10 \%$, high in the germinal centers of preexisting follicles. CD23 staining reveals reduced net of follicular dendritic cells in the follicle-like structures with signs of colonization.

Pathologist Conclusion: pathology findings and immunophenotype are characteristic for mantle cell lymphoma, classic variant, with mainly mantle-cell growth and subtotal involvement of the lymph node.

Repeated bone marrow biopsy (light microscopy): findings are same as in 2011, lymphoid hyperplasia is not seen.

Clinical Diagnosis Revised: Mantle cell lymphoma; stage III, 
with peripheral and visceral lymph nodes and spleen involvement (MIPI=6.5, intermediate risk: age 67, LDH 2 times higher upper normal limit, WBC 7.8x109/L, ECOG=1, Ki-67 10\%). Secondary immune-complex glomerulonephritis (membranoproliferative with polyclonal IgG deposits), nephritic syndrome with impaired renal function.

Treatment and Follow-Up: December 92015 patient was started on Rituximab-Bendamustine (RB) chemotherapy and received 6 courses. After the 6-th course (May 11 2016) she was doing well, no edema, blood pressure $130 / 75 \mathrm{~mm}$ Hg. Hematological response assessed by Cheson criteria could be interpreted as complete remission [27]. Her blood count parameters were stable (Hb $10.0 \mathrm{~g} / \mathrm{L}, \mathrm{WBC} 3.8 \times 109 / \mathrm{L}$ lymphocytes $0.9 \times 109 / \mathrm{L}$ ), proteinuria decreased from 2.86 $\mathrm{g} / 24$ hours to $0.9 \mathrm{~g} / 24$ hours, microhematuria resolved, serum creatinine $108 \mu \mathrm{mol} / \mathrm{L}$. She continues treatment with rituximab maintenance every 2 months (last infusion September 12 2016). At the latest follow-up visit (October 13 2016) she was doing well, no edema, blood pressure $125 / 70 \mathrm{~mm} \mathrm{Hg}$, proteinuria 0.4 $\mathrm{g} / 24$ hours, serum creatinine $105 \mu \mathrm{mol} / \mathrm{L}$.

Final Diagnosis: Mantle cell lymphoma; stage III, with peripheral and visceral lymph nodes and spleen involvement (MIPI=6.5, intermediate risk: age 67, LDH 2 times higher upper normal limit, WBC 7.8x109/L, ECOG=1, Ki-67 10\%), treated with RB chemotherapy, complete remission. Secondary immunecomplex glomerulonephritis (membranoproliferative with polyclonal IgG deposits), partial remission, CKD stage 3a.

\section{Case 2}

Caucasian male, year of birth 1948, first admitted to our nephrology unit September 212015.

Main Complains: edema, decreased urine output, dyspnea at exercise and skin rush.

Previous medical history: inguinal hernia, right leg superficial veins non-occlusive thrombosis with phlebectomy in 2013, taking warfarin, and then aspirin.

History of Present Illness: April 2015 he felt dizziness and experienced seeing spots, his blood pressure was found as high as 200/130 mm Hg. He received ACE-inhibitors and diuretics. His blood pressure decreased to $140 / 80 \mathrm{~mm}$ Hg. Outpatient work-up found proteinuria $3.5 \mathrm{~g} / \mathrm{L}$, ESR $54 \mathrm{~mm} /$ hour, serum creatinine $166 \mu \mathrm{mol} / \mathrm{L}$, total protein $5.0 \mathrm{~g} / \mathrm{dL}$, cholesterol $8.5 \mathrm{mmol} / \mathrm{L}$, other blood chemistry and total blood count parameters within normal range. Prostate-specific antigen, thyroid hormones, CRP and rheumatoid factor - otherwise normal. Electrocardiogram and echocardiography showed nothing but mild left ventricular hypertrophy. Plain chest X-ray unremarkable. Abdomen and kidney ultrasound and abdomen MRI found only moderate hepatomegaly and gall stones. Gastroscopy and colonoscopy revealed gastric polyp, multiple colon polyps and giant cecum polyp (hyperplastic by histology). He was continued on ACEinhibitors, diuretics and aspirin and was doing well till September 2015, when he developed massive edema and was referred to our clinic.
At admission: conscious, alert. Body temperature $36.4^{\circ} \mathrm{C}, \mathrm{RR}$ 17 per minute, pulse regular 64 per minute, BP 140/90 mm Hg. Obese (BMI 32). Skin normally coloured, with few macular rush elements on the low extremities. Massive low extremities, scrotal and penile edema. HEENT otherwise normal. Soft, painless right axillary and left supraclavicular lymph nodes up to $25 \mathrm{~mm}$ in diameter. Lungs: clear. Heart: regular rhythm, no murmur. Abdomen soft, non-tender, bowel sounds normal. Liver, spleen and kidneys not felt. Urination difficulty due to the penile edema, urine output $600 \mathrm{ml} / 24$ hours.

Work-Up: severe nephrotic syndrome (proteinuria $8.6 \mathrm{~g} / 24$ hours, serum total protein $3.7 \mathrm{~g} / \mathrm{dL}$, serum albumin $1.2 \mathrm{~g} / \mathrm{dL}$, cholesterol $11.5 \mathrm{mmol} / \mathrm{L}$ ), serum creatinine $266 \mu \mathrm{mol} / \mathrm{L}$, urea 9.9 mmol/L, LDH 376 U/L, ESR 50 mm/hour, other blood chemistry and total blood count parameters, as well as coagulation tests within normal range.

Serum and urine immunochemistry: massive non-selective glomerular proteinuria, serum IgG deficiency, monoclonal secretion not detected.

\section{Kidney Biopsy}

Light Microscopy: sections of formalin fixed paraffinembedded tissue were stained with H\&E, Masson's trichrome, periodic acid-Shiff and Congo red. 14 glomeruli were found, all of them enlarged, without proliferative changes. Capillary walls thickened, single-contoured (Figure 4). Diffuse-focal interstitial fibrosis and tubular atrophy about $10 \%$ of parenchyma with concomitant lymphohystocyte infiltration in the areas of sclerosis. Arteries with muscle layer hypertrophy and arteriosclerosis, arterioles otherwise normal (Figure 5). Congo red staining was negative.

Immunofluorescence: on unfixed cryo-sections with fluorescein conjugated anti IgA, IgG, IgM, C1q, C3, fibrinogen, lambda and kappa light chains antibodies demonstrated positive $(+++)$ staining for IgG, C3, lambda and kappa light chains on the periphery of capillary loops (Figure 6), and negative staining for IgA, IgM, C1q and fibrinogen.

Pathologists Conclusion: Membranous nephropathy.

\section{Additional Work-Up}

Autoimmune Screening: Anti-phospholipase A2 receptor antibodies, anti-DNA, antinuclear, anticardiolipin, anti- $\beta 2$ glycoptotein antibodies, rheumatoid factor, C3 and C4 within normal range, cryoglobulines not detected. Lupus anticoagulant slightly-positive (1.29 RVU).

Infections Screening: RPR-test for Treponema Pallidum, HBsAg, anti-HCV and anti-HIV-antibodies and tuberculin skin test - all negative, CRP within normal range.

Peripheral Lymph Nodes Ultrasound: multiple crevical, axillary and inguinal hypoechoic lymph nodes $(7-20 \mathrm{~mm}$ in diameter).

Low Extremities Doppler Ultrasound: occlusive thrombosis of distal common femoral vein and long saphenous vein. 
Repeated Gastroscopy with Gastrobiopsy: uncomplicated hiatal hernia, gastroduodenitis, non-epithelial mass 40x15 mm in the fundal part of the stomach.

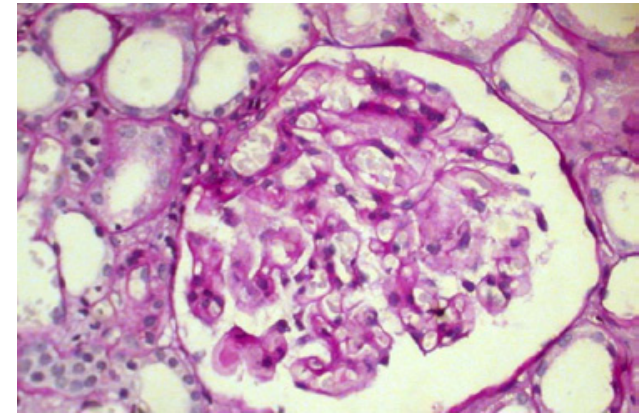

Figure 4: Case 2: Light microscopy. Enlarged glomerulus without proliferative changes, capillary walls thick, single-contoured. PAS x200.

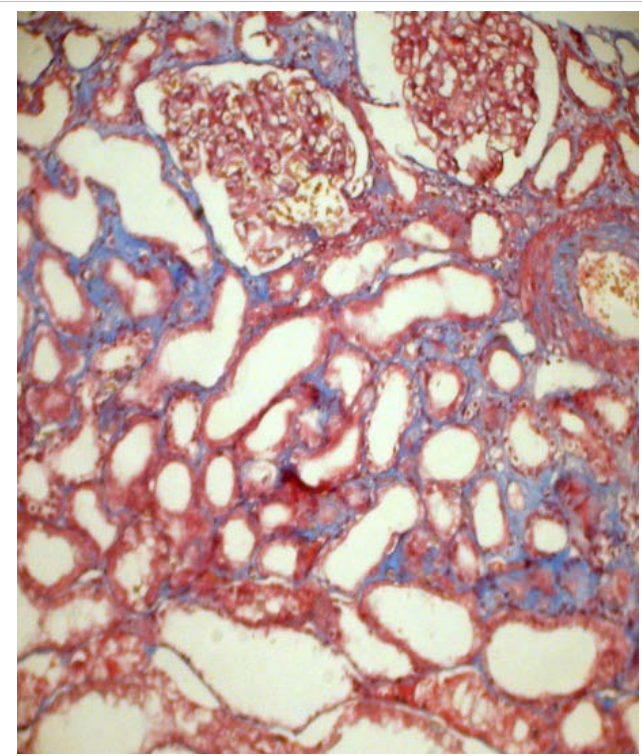

Figure 5: Case 2: Light microscopy. Diffuse-focal interstitial fibrosis and tubular atrophy, artery with muscle layer hypertrophy and arteriosclerosis. Masson x100.

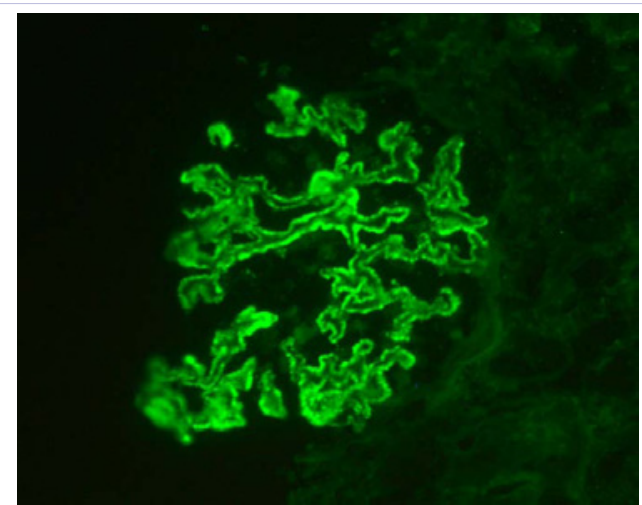

Figure 6: Case 2: Immunofluorescence. Strong positive staining on the periphery of capillary loops. IgG x200.

\section{Gastrobiopsy}

Light Microcopy: in the stomach lining lamina propria dense nodular-diffuse infiltrate, formed by small lymphoid small with round-oval and irregular nuclei is found

Immunohistochemistry: using anti CD3, CD5, CD10, CD20, CD23, BCL-2, Ki-67 and CyclinD1 antibodies: cells of lymphoid infiltrate express CD20 (intensive monomorphic membrane reaction), CyclinD1 (nuclear reaction), BCL-2 (cytoplasmic reaction), co-express $\mathrm{CD} \%$ (membrane reaction). Reaction with the other markers in the neoplasm cells is negative. Admixture of small T-cells (CD3+) presenting with small clusters is found. Proliferative activity index Ki-67 is average $10 \%$ of positive malignant cells.

Pathologist conclusion: pathology findings and immunophenotype are characteristic for mantle cell lymphoma.

\section{Bone Marrow Biopsy}

Light Microscopy: Elements of all three hematopoietic lineages are present, 4 lymphoid intra- and paratrabecular cell clusters.

Immunohistochemistry: neoplastic cells express CD20 (intensive monomorphic membrane reaction), CD5 (membrane reaction), CyclinD1 (intensive monomorphic nuclear reaction) and BCL-2 (cytoplasmic reaction). They are CD10 and BCL-6 negative. CD23 staining reveals reduced net of follicular dendritic cells of preexisting follicles. Small CD3-positive T-cells are dispersed inside the tumor infiltrate.

Pathologist Conclusion: Pathology findings and immunophenotype are characteristic for mantle cell lymphoma.

Clinical Diagnosis: Mantle cell lymphoma; stage IV, with peripheral lymph nodes, bone marrow and gastric involvement (MIPI=7, high risk: age 67, LDH 1.5 times higher upper normal limit, WBC 7.6x109/L, ECOG=2). Secondary immune-complex glomerulonephritis (membranous nephropathy with polyclonal IgG deposits), nephrotic syndrome with impaired renal function.

Treatment and Follow-Up: During hospital stay the patient received antihypertensive medications, diuretics and anticoagulants and antiplatelet agents. His edema subsided, urine output increased, and his right leg veins thrombosis was recanalized. For lymphoma treatment the patient was given 6 cycles of RB (ribomustine and rituximab) since December, 2015 to June, 2016 with subsequent rituximab maintenance. At the latest follow-up visit (October 3 2016) he was doing well, edema almost completely resolved, blood pressure 140/85 mm $\mathrm{Hg}$, peripheral lymph nodes not palpable. His total blood count parameters were normal, proteinuria decreased from $8.6 \mathrm{~g} / 24$ hours to $4.0 \mathrm{~g} / 24$ hours, serum total protein increased from 3.7 $\mathrm{g} / \mathrm{dL}$ to $5.5 \mathrm{~g} / \mathrm{dL}$, serum creatinine decreased from $266 \mu \mathrm{mol} / \mathrm{L}$ to $121 \mu \mathrm{mol} / \mathrm{L}$.

Final Diagnosis: Mantle cell lymphoma; stage IV, with peripheral lymph nodes, bone marrow and gastric involvement (MIPI=7, high risk: age 67, LDH 1.5 times higher upper normal 
limit, WBC 7.6x109/L, ECOG=2), treated with RB chemotherapy. Secondary immune-complex glomerulonephritis (membranous nephropathy with polyclonal IgG deposits), nephrotic syndrome, partial remission, CKD stage $3 \mathrm{a}$.

\section{Discussion}

MCL is relatively rare aggressive lymphoma with occasionally reported renal involvement. 13 out of 17 cases biopsyproven cases described so far represent various patterns of glomerulonephritis. In its turn, 4 out of these 13 cases were diagnosed as MPGN by pathology $[1,12-26]$, and none of them was diagnosed as MN.

Our first case presented with proteinuria, microhematuria and impaired renal function, her kidney biopsy revealed immune-complex MPGN. Given the peripheral and visceral lymph nodes enlargement, weight loss, elevated LDH, high number of serum immune complexes, mild Bence-Jones proteinuria and well-established association of immune-complex MPGN with blood malignancies [8] we suspected lymphoma or lymphoplasmacytic lymphoma, but bone marrow biopsy didn't have any diagnostic yield, peripheral lymph nodes were not available for the biopsy due to the small size, and repeated test didn't detected monoclonal proteins neither in the serum or in urine. At that point we considered thyroid cancer to be causative for lymphadenopathy and immune-complex MPGN; however thyroidectomy with thyroid and regional lymph nodes pathology study ruled out this diagnosis. Patient was doing well under nephroprotective treatment, and demonstrated skin vasculitis and lymph node involvement progression after 4 years of followup. Her neck lymph node biopsy, performed almost 6 years after the first presentation of the disease, was confirmative for MCL. We suppose that MCL was complicated by paraneoplastic MPGN at the onset; however renal manifestations dominated over lymphoma signs and symptoms, which hampered the diagnosis despite of the high index of clinical suspicion and repeated targeted search. Chemotherapy, started after MCL diagnosis lead to the regression of lymph nodes and spleen involvement, and also resulted in the decrease of proteinuria and disappearance of hematuria with the stabilization of renal function. Of interest her serum creatinine already decreased before the chemotherapy start, reflecting the fact she had AKI on the top of CKD. As lymphoid infiltration of kidney was not found by biopsy, we presume that elements of nonspecific interstitial edema were responsible for her AKI at the time of biopsy.

Our second case presented with severe nephrotic syndrome, arterial hypertension and impaired renal function, his kidney biopsy revealed MN. Given the peripheral lymph nodes enlargement, gastric neoplasm, normal anti-phospholipase A2 receptor antibodies level, and well defined paraneoplastic origin of almost $25 \%$ of MN cases [4-6] we suspected gastric malignancy. Gastrobiopsy findings ruled out gastric cancer and were characteristic for MCL; bone marrow biopsy confirmed the diagnosis. Important finding was positive lupus anticoagulant, taken together with two episodes of vein thrombosis this is suggestive for antiphospholipid syndrome. We could not repeat the test for lupus anticoagulant, but this diagnosis (even though not proven) is very likely, as secondary antiphospholipid syndrome was described in patients with lymphomas $[28,29]$. We presume that in this case MCL was complicated by paraneoplastic GN at the onset or soon after the onset, but the severity of renal manifestations masked lymphoma signs and symptoms and defined the diagnostic algorithm. MN pattern, found by kidney biopsy, guided the search for malignant disease, which promptly lead the diagnosis of lymphoma. However, the type of lymphoma was unexpected as MN was not previously described in MCL. Chemotherapy started after the MCL diagnosis resulted in the substantial decrease of proteinuria with the increase of serum total protein and restoration of renal function. The latter reflects CKD with superimposed AKI due to severe nephrotic syndrome. AKI resolved along with its partial remission of NS. It is worthy of special notice, that his serum creatinine decreased more than by half - from $266 \mu \mathrm{mol} / \mathrm{L}$ to $121 \mu \mathrm{mol} / \mathrm{L}$.

\section{Conclusion}

Paraneoplastic glomerulonephritis in MCL is a rare condition, occasionally described in the literature. Renal biopsy is crucial for the diagnosis. In our two patients renal disease manifestations dominated in the clinical presentation and demanded kidney biopsy. Pathology patterns of immune-complex MPGN and MN defined high index of suspicion for malignant disease and guided targeted search, resulted in MCL diagnosis. To our knowledge this is the fifth description of MPGN and first description of MN in patients with MCL. Chemoptherapy for MCL in both cases resulted in partial remission of glomerulonephritis with restoration of renal function.

\section{Acknowlegements}

We thank doctors Olga Vinogradova, Tatiana Makarova, Alina Anilina, Andrey Evsikov, Ivan Lebedinsky and Alla Kovrigina for their help in the diagnostics and treatment of our patients.

\section{References}

1. Da'as N, Polliack A, Cohen Y, Amir G, Darmon D, Kleinman Y, Goldfarb AW.et al. Kidney involvement and renal manifestations in nonHodgkin's lymphoma and lymphocytic leukemia: a retrospective study in 700 patients. Eur J Haematol. 2001;67:158-164.

2. Tornroth T, Heiro M, Marcussen N, Franssila K. Lymphomas diagnosed by percutaneous kidney biopsy. Am J Kidney Dis. 2003;42(5):960-971.

3. Cohen LJ, Rennke HG, Laubach JP, Humphreys BD. The spectrum of kidney involvement in lymphoma: a case report and review of the literature. Am J Kidney Dis. 2010;56(6):1191-1196. doi: 10.1053/j. ajkd.2010.07.009.

4. Ronco PM. Paraneoplastic glomerulopathies: new insights into an old entity. Kidney Int. 1999;56(1):355-377. doi:10.1046/j.15231755.1999.00548.x

5. Hagler KT, Lynch JW Jr. Paraneoplastic manifestations of lymphoma. Clin Lymphoma. 2004;5(1):29-36

6. Cambier JF, Ronco P. Onco-nephrology: glomerular diseases with cancer. Clin J Am Soc Nephrol. 2012; 7(10):1701-1712. doi: 10.2215/ CJN.03770412.

7. Stokes MB, Wood B, Alpers CE. Membranoproliferative 
glomerulonephritis associated with low-grade B cell lymphoma presenting in the kidney. Clin Nephrol. 2002;57(4):303-309.

8. Fervenza FC, Sethi S, Glassock RJ. Idiopathic membranoproliferative glomerulonephritis: does it exist? Nephrol Dial Transplant. 2012;27(12):4288-4299. doi: 10.1093/ndt/gfs288.

9. Li S-J, Chen HP, Chen YH, Zhang Lh, Tu YM, Liu ZH. Renal Involvement in Non-Hodgkin Lymphoma: Proven by Renal Biopsy. PLoS ONE. 2014;9(4):e95190. doi:10.1371/journal.pone.0095190.

10.Zakharova EV, Stolyarevich ES. Clinical Presentation and Pathology Spectrum of Kidney Damage in Non-Hodgkin Lymphoma/Leukemia and Lymphoplasmacytic Lymphomas. J Leuk. 2015;3(4):201. doi:10.4172/2329-6917.1000201.

11. Swerdlow S.H., Campo E, Harris N.L, Jaffe E.S, Pileri, Stein H, et al World Health Organization (WHO) (2008) classification of tumours of haematopoietic and lymphoid tissues. Fourth Edition.

12. Rerolle JP, Thervet E, Beaufils H, Vincent F, Rousselot P, Pillebout E, et al. Crescentic glomerulonephritis and centrocytic lymphoma. Nephrol Dial Transplant. 1999;14(7):1744-1745.

13. Karim M, Hill P, Pillai G, Gatter K, Davies DR, Winearls CG. Proliferative glomerulonephritis associated with mantle cell lymphomanatural history and effect of treatment in 2 cases. Clin Nephrol. 2004;61(6):422-428.

14. Davies J, Healey DA, Wood KM Jones K, Kanagasundaram NS. Acute renal failure due to mantle cell lymphoma - a case report and discussion of the literature. Clin Nephrol. 2007;67(6):394-396.

15. Colak N, Dede F, Canbakan B Odabaș AR, Akyürek N. Acute tubulointerstitial nephritis associated with mantle cell lymphoma presented as acute renal failure. Nephrology. 2007;12(1):107-108.

16. Wong CF, Mohteshamzadeh M, Arsalanizadeh B, Dutt T, Shawki $\mathrm{H}$, Khine MM, et al. Successful treatment of focal segmental glomerulosclerosis in association with mantle cell lymphoma. Ren Fail. 2007;29(3):363-366. doi:10.1080/08860220601166636.

17. Sellin L, Friedl C, Klein G, Waldherr R, Rump LC, Weiner SM. Acute renal failure due to a malignant lymphoma infiltration uncovered by renal biopsy. Nephrol Dial Transplant. 2004;19(10):2657-2660. doi: $10.1093 /$ ndt/gfh201.

18. Lubas A, Mróz A, Smoszna J, Niemczyk S. Membranoproliferative glomerulonephritis, mantle cell lymphoma infiltration, and acute kidney injury. Int Urol Nephrol. 2013;45(5):1489-1494. doi:10.1007/ s11255-012-0210-4.
19. Montoro J, Jatem E, Abrisqueta P, Castillo N, Bobillo S, et al. Acute Renal Failure Due to Membranoproliferative Glomerulonephritis and Kidney Tumoral Infiltration in a Patient with Mantle Cell Lymphoma. Hematol Transfus Int J. 2015;1(1):00004. doi: 10.15406/htij.2015.01.00004.

20. Abeysekera RA, Wazil AW, Nanayakkara N, Ratnatunga N, Fernando KM, Thinnarachchi J. Mantle cell lymphoma first presenting as immune complex-mediated glomerulonephritis: a case report. Journal of Medical Case Reports. 2015;9:115. doi: 10.1186/s13256-0150583-y.

21. Wang J, Li L , Chen F, Yin Q, Zhang X, Liu F. Antineutrophil Cytoplasmic Antibody-negative Pauci-immune Crescentic Glomerulonephritis and Mantle-cell Lymphoma. A Case Report and Review of the Literature. WIMJ Open. 2014;1(3):114-116. doi: 10.7727/wimjopen.2014.198.

22. Chu JR, Dierksen JE, Glass WF, Aisenberg GM. Association of membranoproliferative glomerulonephritis with mantle cell lymphoma. BMJ Case Reports. 2013;doi:10.1136/bcr-2013-009730.

23. Khow KS, Yong AS, Yong TY, Kuss BJ, Barbara JA, Li JY. Minimal change disease associated with newly diagnosed mantle cell lymphoma. Renal Failure. 2014;36(4):634-637. doi.org/10.3109/088602 2X.2014.883905

24. Lee HJ, Seo JW, Cho HS, Kang Y, Bae EJ, Lee DW et al. Renal involvement of mantle cell lymphoma leading to end stage renal disease. Hemodial Int. 2012;16(1):104-108. doi: 10.1111/j.1542-4758.2011.00612.x.

25. Peddi S, Ram R, Kataru SR, Chennu KK, Nandyala R, Kottu R, et al. Acute renal failure in a patient with mantle cell lymphoma. Hemodial Int. 2015;19(3): doi: 10.1111/hdi.12229.

26. Hill P, Somerville C. An 80-year-old man with renal insufficiency, proteinuria, hematuria, hemiparesis, and pleuritis. Am J Kidney Dis. 2004;44(6):1121-1125.

27. Cheson BD, Horning SJ, Coiffier B, Shipp MA, Fisher RI, Connors JM, et al: Report of an International Workshop to Standardize Response Criteria for Non-Hodgkin's Lymphomas. J Clin Oncol 1999;17(4):1244. doi: 10.1200/jco.1999.17.4.1244.

28. Genvresse I, Lüftner D, Späth-Schwalbe E, Buttgereit F. Prevalence and clinical significance of anticardiolipin and anti-beta2-glycoprotein-I antibodies in patients with non-Hodgkin's lymphoma. Eur J Haematol. 2002;68(2):84-90.

29. Pusterla S, Previtali S, Marziali S, Cortelazzo S, Rossi A, Barbui T, et al. Antiphospholipid antibodies in lymphoma: prevalence and clinical significance. Hematol J. 2004;5(4):341-346. 